\title{
Changes in New Zealand transport mode choices over time by size of city
}

\author{
M. Keall ${ }^{1}$, R. Chapman ${ }^{2}$ \& P. Howden-Chapman ${ }^{1}$ \\ ${ }^{I}$ Centre for Sustainable Cities, University of Otago, New Zealand \\ ${ }^{2}$ Victoria University, New Zealand
}

\begin{abstract}
New Zealand cities have similarities with many North American and Australian cities in terms of their form. Typically, they are characterised by urban sprawl, as most private housing consists of free-standing dwellings with a relatively large section (yard). This form of development potentially leads to dependence on cars as a mode of transport, generating in New Zealand some of the highest carownership rates in the world. In the light of concerns about global warming, recent research has highlighted that the nature of urban development is a major contributor to climate change and that changes in urban form offer the potential to cut greenhouse emissions. Analysis of New Zealand travel survey data over the period 1989-2006 showed a disturbing trend nationally of increasing use of cars, accompanied by large decreases in cycling and walking for children aged 5-14. This poses concerns not only about the negative environmental effects of driving, but also about New Zealand's growing obesity epidemic, to which sedentary lifestyles contribute. The current study looked at travel survey data according to city size, showing that the reduction in children's walking and cycling appears to be a problem that is largest in the bigger cities, but still a concern in smaller cities. In contrast, small towns and rural areas showed no such reduction in children's walking and cycling. This contrast in transport mode choices is hypothesised to be associated with changes in the urban form of the larger cities over the time period studied, which may not have been so apparent in smaller urban centres. Further testing of this hypothesis is required to identify other societal changes happening concurrently, but the fact that small towns and rural areas have not seen a reduction in active transport choices suggest urban form as an influence, the implications of which need to be considered by town planners.
\end{abstract}

Keywords: urban form, active transport modes, mode choice, urban sprawl. 


\section{Introduction}

New Zealand cities have a number of similarities with many North American and Australian cities in terms of their form. Typically, they are characterised by urban sprawl, as most private housing consists of free-standing dwellings with a relatively large section (yard). As with many other developed countries, the rising cost of housing in New Zealand during the recent economic boom was often framed narrowly as an affordability problem, largely due to the high cost of land, to which removing any urban limits was seen as a partial solution. The argument used by property developers was that regulation of urban limits artificially inflates land prices [1]. If peri-urban land is opened to housing development, the cost of land is reduced by increasing the supply. Two potential problems with this strategy are the carbon emissions associated with extra travel necessitated by such development, and the extra cost of travel in terms of fuel, time spent, increased travel-related injuries and opportunities lost due to the barriers of greater distances from homes to other important settings. The former issue is of great importance, given growing evidence of the urgency of climate change mitigation [2]. Moreover, by 2050, New Zealand may need to reduce greenhouse gas emissions by about $90 \%$, with accompanying significant changes in economic and social behaviours, including transport patterns [3, 4]. In addition, increased vehicle travel intensifies pressure for further road building, which is not only itself carbon-intensive, but also likely to be largely selfdefeating, as it induces more traffic and congestion [5].

There is a wide and growing research literature that explores the relationship between urban sprawl, the built environment and population health [6-11]. There is also a substantial literature which explores the complex relationship between urban form and travel behaviours [12-17], which in turn matter for health [18-23].

One study, also applied to New Zealand data, has explored the relationship between town size and physical activity [24]. The study found that city dwellers were more likely to be physically inactive; however the study identified the need for further research to examine the relationship between town size and particular forms of physical activity, including transport-related physical activity.

Analysis of New Zealand travel survey data [25] over the period 1989 to 2006 has indicated a disturbing trend nationally showing increasing proportions of travel time driving, accompanied by large decreases in cycling and walking for children aged 5 to 14 . There is accompanying evidence that access to driving private cars reduces the proportion of time spent walking. For example, analysis of NZ Travel Survey data has shown that people without driving licences walk considerably more than those with driving licences [26]. There will also be reverse causation in some cases (viz, some people who tend to walk more see no need to obtain a driver's licence). Nationally, NZ travel survey data indicate that children's passenger travel in private cars has replaced much travel that was previously active (walked and cycled). These changes in mode share pose concerns not only about the negative environmental effects of increased driving, 
but also regarding a growing obesity epidemic that affects New Zealanders, to which sedentary lifestyles contribute [27].

What still needs to be clarified is the effect of the urban form on people's mode choices, particularly their propensity to undertake active travel rather than use a car. Until we understand the influence of the urban form, the effectiveness of urban planning policies in reducing carbon emissions and enhancing health will remain unclear.

\section{Methods}

\subsection{New Zealand travel survey}

This analysis uses data from a national personal interview travel survey, the New Zealand Travel Survey, which was conducted initially in 1997-98 with a sample of approximately 14,000 people from 7,000 randomly selected households [28, 29]. Since 2002, the survey has been ongoing, collecting data from approximately 2,200 households per year. The survey has national coverage and is based on interviews conducted face-to-face in participants' homes. The survey has maintained a response rate of between $70 \%$ and $75 \%$.

All residents in the sampled houses were asked to describe all of their travel for two selected days. As these days were spread out over a whole year of data collection, information could be scaled up to represent a year's travel by all New Zealanders from this representative sample of households and days of travel. For each trip origin and destination, map coordinates were obtained (to "digitise" the addresses) as well as data on the time, date, travel mode, and purpose of the trip. Data on respondent age, gender, profession, income, family type, and vehicle ownership were also recorded.

The more recent survey data analysed in this paper, gathered between 2002 and 2006, were of a similar form to those collected in the earlier survey, but were mainly entered on laptop computers at the time of the interview, enabling more efficient coding and digitising of addresses to be undertaken. Sample sizes in terms of trips surveyed for the disaggregations of the data used are shown in Table 1.

\subsection{Grouping of population centres}

The analysis of travel of the occupants of population centres of three different sizes was achieved by defining classes of cities/towns according to standard definitions of New Zealand population centres [30] as follows:

- Main Urban Areas ('MUAs'): Cities with population of 30,000 or more - e.g., Auckland, Hamilton, Napier

- Secondary Urban Areas ('SUAs'): Cities with population of between 10,000 and 30,000 - e.g., Masterton, Taupo, Pukekohe

- Minor Urban and rural ('rural'): Towns with population of less than 10,000 and rural areas - e.g., Westport, Thames, Kaikoura

Minor Urban and rural areas (referred to as "rural") have $24 \%$ of the New Zealand population, but they account for $30 \%$ of the total distance driven. This 
reflects the larger distances people living in these areas need to travel. Secondary Urban Areas (SUAs) in contrast are often quite self-contained, with many facilities and key locations within a relatively confined area. The larger cities (MUAs) have grown considerably over the last few decades through new housing developments on their edges, leading to considerable sprawl [31, 32].

\section{Results}

The following estimates were obtained by classifying the respondents by age group and by the size of the population centre where they lived. For each survey, the percentage of time travelling was calculated across the modes: walk; car driver (for groups aged 15 years and over); car passenger; bicycle; train/bus; and other (that includes air travel, ferry travel, and other more unusual modes). The percentage of time travelled using each given mode in 1997/98 was subtracted from the percentage of time estimated for that mode from the 2002-2006 survey to give an estimate of the change in modal travel over that period (as represented by the last column of Table 1).

Table 1 shows changes occurring over the approximately eight years between the surveys for children aged less than 10 years. Note that parents provided the information on the travel for most of these children, which may mean some underestimation of the active travel. However, the survey method was consistent for both survey periods. The data suggest that the nationwide pattern of car passenger travel replacing the time children spend walking for transport is more pronounced for children in the larger cities (MUAs). Table 1 shows a similar pattern of switching from walking to passenger trips for children aged 10-14.

The patterns for the age group 15-19, shown in Table 1, suggest slightly different patterns of change from the younger age groups. The travel experiences of this age group are likely to be unique as they have reached the legal age for learning to drive (Young people in New Zealand can get a provisional driving licence at 15 years old) [33]. Most notably, in this time period, teenagers in secondary urban areas appear to have experienced a significant shift away from time spent cycling and using public transport to time spent in cars as passengers. This change seems rather dramatic compared to the other changes shown, but it was also a feature of the travel of young adults in these areas, who experienced a $10 \%$ relative increase in travelling time as passengers, perhaps representing a more fundamental change in mode choice. In contrast, there appears to have been a reduction in time spent as motor vehicle passenger by teenagers in rural areas.

Figure 1 provides estimates of changes in travel modes for adults aged 30-59. The most striking feature of the graph is the reduction (around 5\%) in the proportion of time travelling as a car passenger in rural areas, for which travelling as a driver appears to be largely substituted. This phenomenon is also apparent for the other adult age groups in rural areas and might reflect a growing tendency for rural people to drive with lower occupancy rates in their vehicles than eight years previously. Further research is required to identify why this has been occurring. 
Table 1: $\quad$ Estimates from NZ Travel Surveys 1997-98 and 2002-06 by level of urbanisation of area of residence and respondent age: number of sampled trips; \% of total time travelling; change in the percent between the surveys. "Other" modes are not shown due to small samples (but the denominators of the percentages in columns 6 and 7 include the other modes).

\begin{tabular}{|c|c|c|c|c|c|c|c|}
\hline $\begin{array}{l}\text { Age } \\
\text { group }\end{array}$ & Area & Mode & n 97-98 & n $02-06$ & $\begin{array}{l}\% 97- \\
98\end{array}$ & $\begin{array}{l}\text { \%02- } \\
06\end{array}$ & change \\
\hline \multirow[t]{12}{*}{$0-9$} & \multirow[t]{4}{*}{ MUA } & Walk & 2080 & 1055 & $18 \%$ & $11 \%$ & $-7 \%$ \\
\hline & & Passenger & 8341 & 5990 & $79 \%$ & $85 \%$ & $6 \%$ \\
\hline & & Bicycle & 156 & 84 & $1 \%$ & $0 \%$ & $-1 \%$ \\
\hline & & Train/bus & 93 & 82 & $1 \%$ & $2 \%$ & $0 \%$ \\
\hline & \multirow[t]{4}{*}{ SUA } & Walk & 326 & 172 & $16 \%$ & $14 \%$ & $-2 \%$ \\
\hline & & Passenger & 1272 & 966 & $74 \%$ & $77 \%$ & $3 \%$ \\
\hline & & Bicycle & 50 & 32 & $2 \%$ & $2 \%$ & $-1 \%$ \\
\hline & & Train/bus & 40 & 14 & $6 \%$ & $8 \%$ & $2 \%$ \\
\hline & \multirow[t]{4}{*}{ Rural } & Walk & 880 & 498 & $11 \%$ & $10 \%$ & $0 \%$ \\
\hline & & Passenger & 4005 & 2999 & $76 \%$ & $77 \%$ & $0 \%$ \\
\hline & & Bicycle & 97 & 103 & $1 \%$ & $3 \%$ & $2 \%$ \\
\hline & & Train/bus & 296 & 224 & $11 \%$ & $9 \%$ & $-2 \%$ \\
\hline \multirow[t]{12}{*}{$10-14$} & \multirow[t]{4}{*}{ MUA } & Walk & 1523 & 1036 & $27 \%$ & $22 \%$ & $-5 \%$ \\
\hline & & Passenger & 2967 & 2581 & $51 \%$ & $64 \%$ & $13 \%$ \\
\hline & & Bicycle & 574 & 291 & $8 \%$ & $5 \%$ & $-3 \%$ \\
\hline & & Train/bus & 378 & 197 & $13 \%$ & $7 \%$ & $-6 \%$ \\
\hline & \multirow[t]{4}{*}{ SUA } & Walk & 221 & 192 & $25 \%$ & $28 \%$ & $3 \%$ \\
\hline & & Passenger & 455 & 461 & $46 \%$ & $47 \%$ & $1 \%$ \\
\hline & & Bicycle & 124 & 60 & $13 \%$ & $5 \%$ & $-8 \%$ \\
\hline & & Train/bus & 46 & 39 & $14 \%$ & $20 \%$ & $6 \%$ \\
\hline & \multirow[t]{4}{*}{ Rural } & Walk & 669 & 481 & $14 \%$ & $17 \%$ & $4 \%$ \\
\hline & & Passenger & 1372 & 1244 & $51 \%$ & $47 \%$ & $-4 \%$ \\
\hline & & Bicycle & 260 & 212 & $7 \%$ & $5 \%$ & $-2 \%$ \\
\hline & & Train/bus & 359 & 282 & $27 \%$ & $30 \%$ & $3 \%$ \\
\hline \multirow[t]{8}{*}{$15-19$} & \multirow[t]{5}{*}{ MUA } & Walk & 1483 & 1039 & $27 \%$ & $24 \%$ & $-2 \%$ \\
\hline & & Driver & 1502 & 1187 & $24 \%$ & $26 \%$ & $2 \%$ \\
\hline & & Passenger & 1811 & 1415 & $31 \%$ & $33 \%$ & $2 \%$ \\
\hline & & Bicycle & 288 & 77 & $4 \%$ & $1 \%$ & $-3 \%$ \\
\hline & & Train/bus & 336 & 278 & $13 \%$ & $12 \%$ & $-1 \%$ \\
\hline & \multirow[t]{3}{*}{ SUA } & Walk & 155 & 154 & $16 \%$ & $14 \%$ & $-2 \%$ \\
\hline & & Driver & 187 & 219 & $22 \%$ & $21 \%$ & $-1 \%$ \\
\hline & & Passenger & 289 & 310 & $40 \%$ & $60 \%$ & $20 \%$ \\
\hline
\end{tabular}


Table 1: $\quad$ Continued.

\begin{tabular}{|c|c|c|c|c|c|c|c|}
\hline $\begin{array}{l}\text { Age } \\
\text { group }\end{array}$ & Area & Mode & n $97-98$ & n 02-06 & $\begin{array}{l}\text { \%97- } \\
98\end{array}$ & $\begin{array}{l}\text { \%02 } \\
06\end{array}$ & change \\
\hline & \multirow{7}{*}{ Rural } & Bicycle & 69 & 25 & $*$ & $*$ & $*$ \\
\hline & & Train/bus & 13 & 8 & $*$ & $*$ & $*$ \\
\hline & & Walk & 433 & 382 & $15 \%$ & $16 \%$ & $1 \%$ \\
\hline & & Driver & 750 & 510 & $25 \%$ & $26 \%$ & $1 \%$ \\
\hline & & Passenger & 679 & 730 & $44 \%$ & $38 \%$ & $-6 \%$ \\
\hline & & Bicycle & 64 & 77 & $3 \%$ & $3 \%$ & $0 \%$ \\
\hline & & Train/bus & 84 & 129 & $12 \%$ & $15 \%$ & $2 \%$ \\
\hline
\end{tabular}

* indicates insufficient data on which to base an estimate.

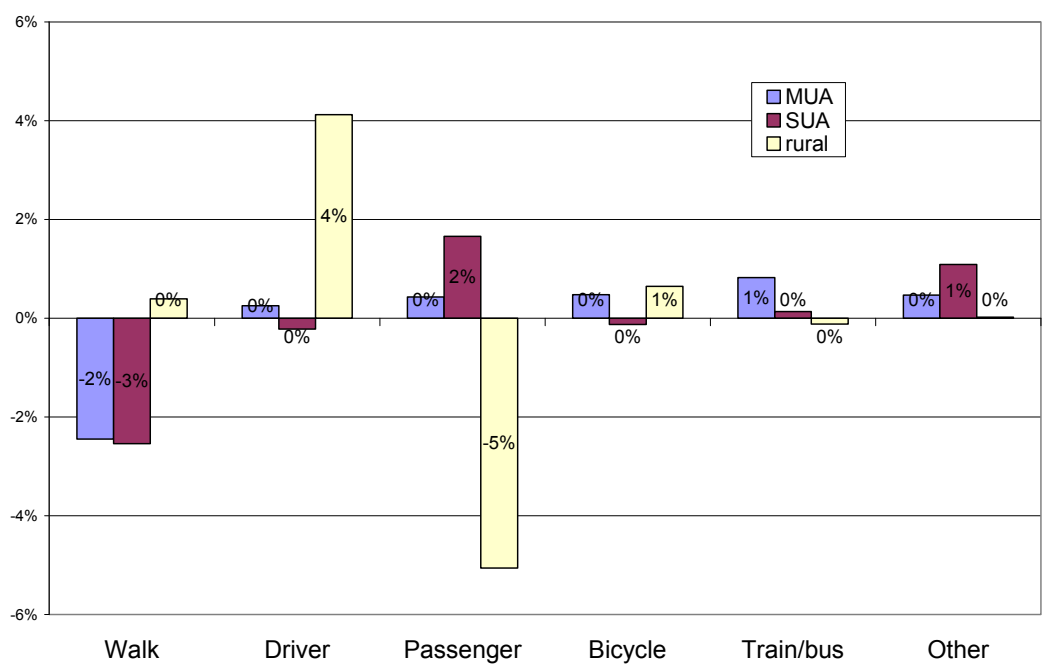

Figure 1: Change in percentage of time travelling $97 / 98$ to $03 / 06$ for adults aged 30-59.

\section{Discussion}

The major limitation of this analysis is that the changes in mode choice vary with city size, but urban form cannot be assumed to be causing these modal shifts. The key finding from this analysis is the observed shift away from active transport by New Zealand children, a shift that appears to be most prominent in major urban areas but not so apparent in smaller towns and rural areas. The potential for the sort of development seen recently in larger New Zealand cities to foster an 'obesogenic environment' is therefore hinted at by these data. 
This finding also provides a motivation for exploring the reasons why towns of different size are experiencing different changes in their travel mode over recent years. Processes that might be operating differently for larger cities include changes in urban characteristics such as walkability, destination accessibility and public transport access; investment in infrastructure such as roads and public transport; relative pricing changes for the different modes; socioeconomic processes and demographic changes such as changes to workforce locations, working hours and educational institutions and childcare service delivery; and cultural or symbolic shifts in how the modes are valued by people in different places. These changes are likely to have differential impacts on different socio-economic and ethnic groups [34]. Future research will look more closely at these other contributing influences and can potentially clarify the role of urban form in creating a more car-reliant culture, particularly amongst children.

\section{References}

[1] Grimes A, Yun L. Spatial Determinants of Land Prices in Auckland: Does the Metropolitan Urban Limit Have an Effect? Wellington: Motu Economic and Public Policy Research; 2007.

[2] Hansen J. Tipping point: Perspective of a climatologist. State of the Wild 2008-2009 Wildlife Conservation Society; 2008.

[3] Chapman R. Transitioning to low-carbon urban form and transport in New Zealand. Political Science 2008; 60(June):89-98.

[4] Chapman R, Boston J. The Social Implications of Decarbonising New Zealand's Economy. Social Policy Journal of New Zealand. 2007 July; 31:104-36.

[5] Goodwin P. Solving Congestion: Inaugural lecture for the Professorship of Transport Policy, University College London, 23 October 1997. 1997 [cited; Available from: http://www2.cege.ucl.ac.uk/cts/tsu/pbginau.htm

[6] Brownson RC, Haire-Joshu D, Luke DA. Shaping the context of health: A review of environmental and policy approaches in the prevention of chronic diseases. Annual Review of Public Health. 2006; 27:341-70.

[7] Frank LD, Sallis JF, Conway TL, Chapman JE, Saelens BE, Bachman W. Many pathways from land use to health - Associations between neighbourhood walkability and active transportation, body mass index, and air quality. Journal of the American Planning Association. 2006 Win; 72(1):75-87.

[8] Giles-Corti B. People or places: What should be the target? Journal of Science and Medicine in Sport. 2006; 9:357-66.

[9] Kelly-Schwartz AC, Stockard J, Doyle S, Schlossberg M. Is sprawl unhealthy? A multilevel analysis of the relationship of metropolitan sprawl to the health of individuals. Journal of Planning Education and Research. 2004 Win; 24(2):184-96. 
[10] Lake A, Townshend T. Obesogenic environments: exploring the built and food environments. Journal of the Royal Society for the Promotion of Health. 2006 Nov; 126(6):262-7.

[11] Sallis JE, Cervero RB, Ascher W, Henderson KA, Kraft MK, Kerr J. An ecological approach to creating active living communities. Annual Review of Public Health. 2006; 27:297-322.

[12] Ewing R, Cervero R. Travel and the built environment - A synthesis. Land Development and Public Involvement in Transportation; 2001. p. 87-114.

[13] Ewing R, Schieber R, Zegeer C. Urban sprawl as a risk factor in motor vehicle occupant and pedestrian fatalities. American Journal of Public Health. 2003; 93(9):1541-5.

[14] Kenworthy JR, Laube FB. Automobile dependence in cities: An international comparison of urban transport and land use patterns with implications for sustainability. Environmental Impact Assessment Review. 1996; 16(4-6):279-308.

[15] Leslie E, Coffee N, Frank L, Owen N, Bauman A, Hugo G. Walkability of local communities: Using geographic information systems to objectively assess relevant environmental attributes. Workshop on New Approaches to Researching Environmental Justice; 2003 Oct; Vancouver, CANADA; 2003. p. 111-22.

[16] Owen N, Cerin E, Leslie E, Dutoit L, Coffee N, Frank LD, et al. Neighbourhood walkability and the walking behaviour of Australian adults. American Journal of Preventive Medicine. 2007 Nov; 33(5):387-95.

[17] Pearce J, Witten K, Bartie P. Neighbourhoods and health: a GIS approach to measuring community resource accessibility. Journal of Epidemiology and Community Health. 2006 May; 60(5):389-95.

[18] Brown AL, Khattak AJ, Rodriguez DA. Neighbourhood types, travel and body mass: A study of new urbanist and suburban neighbourhoods in the US. Urban Studies. 2008 Apr; 45(4):963-88.

[19] Ewing R, Schmid T, Killingsworth R, Zlot A, Raudenbush S. Relationship between urban sprawl and physical activity, obesity, and morbidity. American Journal of Health Promotion. 2003 Sep-Oct; 18(1):47-57.

[20] Frank L, Andresen M, Schmid T. Obesity relationships with community design, physical activity, and time spent in cars. American Journal of Preventive Medicine. 2004; 27(2):87-96.

[21] Handy SL, Boarnet MG, Ewing R, Killingsworth RE. How the built environment affects physical activity - Views from urban planning. American Journal of Preventive Medicine. 2002 Aug; 23(2):64-73.

[22] Lopez R. Urban sprawl and risk for being overweight or obese. American Journal of Public Health. 2004 Sep; 94(9):1574-9.

[23] Vandegrift D, Yoked T. Obesity rates, income, and suburban sprawl: An analysis of US states. Health \& Place. 2004 Sep; 10(3):221-9.

[24] Badland H, Schofield G. Understanding the relationship between town size and physical activity levels: A population study. Health \& Place. 2006 Dec; 12(4):538-46. 
[25] Ministry of Transport. Comparing travel modes: Household Travel Survey. 2008 [cited; v1.4 revised Jan 2008]. Available from: http://www.transport.govt.nz/ongoing-travel-survey-index/

[26] Ministry of Transport. Walking for transport: Ongoing New Zealand Household Travel Survey 2003 - 2007. Wellington, New Zealand; 2008.

[27] Grant BC, Bassin S. The challenge of paediatric obesity: more rhetoric than action. N Z Med J. 2007; 120(1260).

[28] Keall MD, Povey LJ. Travel Survey Highlights 1997/98. Wellington, New Zealand: Land Transport Safety Authority; 2000.

[29] Povey LJ, Keall MD. Travel Survey Report 1997/98. Wellington, New Zealand: Land Transport Safety Authority; 2000.

[30] Statistics New Zealand. 2006 Census - Chapter 6: Geographic definitions. In: Statistics New Zealand, editor; 2007.

[31] Thompson-Fawcett M, Carter C. Sustainable Urban Layout? New Zealand's diverse strategies. In: Freeman C, Thompson-Fawcett M, editors. Living Space: Towards sustainable settlements in New Zealand. Otago University Press; 2003. p. 195-220.

[32] Arbury J. From Urban Sprawl to Compact City: An analysis of urban growth management in Auckland [Unpublished Masters Thesis]: University of Auckland; 2005.

[33] Langley JD, Wagenaar AC, Begg DJ. An evaluation of the New Zealand graduated driver licensing system. Accident Analysis and Prevention. 1996; 28(2): 139-46.

[34] Howden-Chapman P. Restructuring Cities to Reduce Inequalities: rethinking urban environments and health. Wellington: Public Health Advisory Committee; 2008. 